\title{
Substance use among young people in urban environments
}

\author{
I. S. Obot, S. Saxena (Editors) \\ Geneva: World Health Organization (2005)
}

In their extensive review published last year, Galea and Vlahov (2005) state that "urbanization is likely the single most important demographic shift worldwide during the past century and in the new century, and it represents a sentinel change from how most of the world's population lived for the past several thousand years". The purpose of the study of the influence of urbanization on health is to define how the fact of living in an urban physical and social environment may affect the health of the population.

The aim of this book edited by Obot and Saxena is to present different views on the interrelationship between urbanization and substance use among young people from different countries and social realities. For that purpose, they asked researchers in eight countries (Nigeria, South Africa, Brazil, Canada, Mexico, United States, Israel and Japan) from four WHO regions to write country-specific chapters. Additionally to those, there is one chapter dedicated to the links between urbanization and substance use among youth and another on prevention from the perspective of addressing childhood problem behaviors. The closing chapter of the book, written by the editors, is a summary devoted to research priorities and public health issues.

This book gives a broad overview of this important subject from a large perspective that includes not only the demographic but also the social and economic contexts that influ- ence the use of substances among urban youth. Obviously, one of the highlights of this book are the differences between countries with a high rate of urbanization during the last quarter of the twentieth century (like Nigeria, for example, where the urban population increased from 23 to $50 \%$ between 1975 and 2000) and those already highly urbanized like Canada or the USA that showed little change in their percentages of urban population during the same period. All chapters include a good literature review on urbanization and they can be read independently. Even though this is an important advantage for readers looking for specific data, the problem is that, when reading the whole book, the introduction on the importance of urbanization in most chapters tends to be repetitive.

Although it is clear that books such as this one (based on different chapters written by different authors) do not need to be scientifically sound but rather informative in its approach, it is however a pity that most of the tables and figures displayed are often difficult to interpret, lack important information, and seem to have been done without much care in the layout.

Nevertheless, overall this is an interesting book that provides a broad overview of the influence of urbanization on substance use among young people.
Joan-Carles Surís

IUMSP

GRSA

17, rue du Bognon

1005 Lausanne, Suisse

e-mail: Joan-Carles.Suris@chuv.ch

Galea S, Vlahov D (2005). Urban health: evidence, challenges, and directions. Annu Rev Public Health 26: 341-65. 